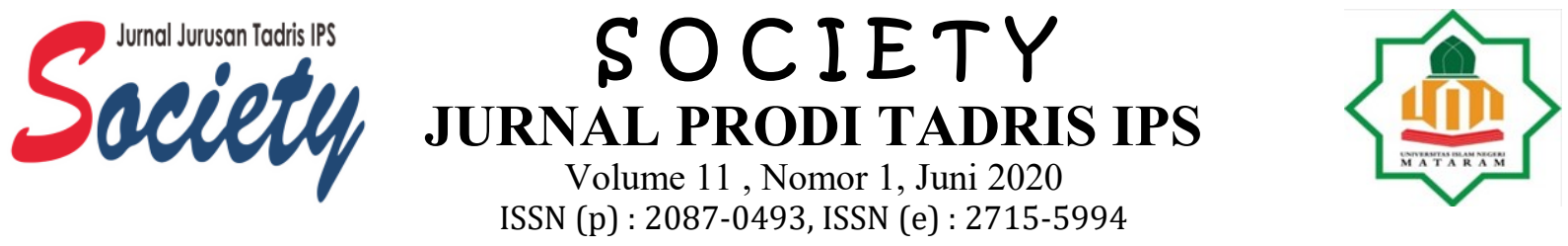

\section{COMMON ERROR IN USE CONJUNCTION IN WRITING}

\author{
Najamuddin \\ Prodi TBI Fakultas Tarbiyah dan Keguruan UIN Mataramm, Indonesia \\ E-mail: najamuddin@uinmataram.ac.id
}

Diterima 15 Mei 2020 --- Disetujui 18 Juni 2020 --- Dipublikasikan 30 Juni 2020

\begin{abstract}
Conjunction is used to make a sentence which having the cohesion and coherence in text. The absence of the right conjunction will result in having illogical meaning, and the message. Because of the important role of conjunctions in the writing process, this study aims to reveal the students' common errors on the use of conjunction in their writing, and investigate types of errors that occur most frequently in students' writing.

This part contains the necessary conjunction In grammar, a conjunction (abbreviated CONJ or CNJ) is a part of speech that connects words, phrases, or clauses that are called the conjuncts of the conjoining construction. The term discourse marker is mostly used for conjunctions joining sentences. This definition may overlap with that of other parts of speech, so what constitutes a "conjunction" must be defined for each language. In general, a conjunction is an invariable grammatical particle and it may or may not stand between the items in a conjunction.
\end{abstract}

A knowledge of words, phrases, clauses is essential to good writing and speaking, but it doesn't mean neglected the other part of grammar. The correction of writing and speaking is to concentrate on what we are saying rather than on how we are saying it.

Keywords: he Error in the use Conjunction.

\section{A. INTRODUCTION}

In written and spoken English can often be in different ways. The complex nature of language sometimes makes write difficult. Words often become confusing when they have similar forms. Indeed, an author may have correct meaning in mind, but an incorrect word choice can alter the meaning of sentence or even make it totally illogical. That is why a writer must continually strive for precise expression of language by finding the exact word to express a specific meaning. A knowledge of words, phrases, clauses is essential to good written and spoken, but it doesn't mean neglected the other part of grammar. The correction of writing and speaking is to concentrate on what we are saying rather than on how we are saying it.

Basically writers must have understanding of basic material with simple and complex words for example, naming words, asserting words, connecting words, descriptive words. Therefore, a knowledge of the properties and functions of the 
different kinds of words can make writers rich to develop their written. Words serve different purposes in language. Function of words make language has meaning, coherent and readable. Basically, students have to know both some number of words to understand what they read.

Learning language context which refers to the textual or place in which a particular word or structure can be found. Learning contexts constrain the ways learners approach learning tasks.

Theoretical background is simply limited to use the right conjunction when it used in sentences. In grammar, a conjunction (abbreviated CONJ or CNJ) is a part of speech that connects words, phrases, or clauses that are called the conjuncts of the conjoining construction. The term discourse marker is mostly used for conjunctions joining sentences. This definition may overlap with that of other parts of speech, so what constitutes a "conjunction" must be defined for each language. In general, a conjunction is an invariable grammatical particle and it may or may not stand between the items in a conjunction (References Mei 2017 https://en.wikipedia.org/ wiki/Conjunction (grammar).

The complex nature of language sometimes makes writing difficult. Words often become confusing when they have similar forms and sounds (Oelschlaeger and Damico, 2000)10. Indeed, an author may have correct meaning in mind, but an incorrect word choice can alter the meaning of sentence or even make it totally illogical. That is why a writer must continually strive for precise expression of language by finding the exact word to express a specific meaning.
An interesting question then raised, how do students acquire so many new words? An extensive study indicates that the answer to this question is through incidental learning. It means that the learning is conducted through exposure and interaction with very complex and rich oral language and by encountering lots of new words in text, either through their own reading or by being read. However, such incidental encounters may not result that students will gain in depth meanings of specific words.

The present content analysis tends to investigate potential use the right conjunction. Content analysis is a research to identify the meaning from certain document (Mile, Huberman, Saldana, 2013). The data collection was conducted by looking at samples simply limited to use the right conjunction when it used in sentences and analysis them qualitatively by investigating the meaning and the use in some sentences to know meaning and the contexts (Stahl \& Nagy, 2000). The right conjunction in sentences are prescribed in order to identified as what lexically and contextually prescribed. The use of the conjunction in the sentences will provide clear understanding in spoken and written.t

\section{B. DISCUSSION.}

The italicized words in the preceding paragraph are conjunctions. Like preposition, conjunctions are connecting words. They connect words, phrase, or clauses. There are There are two main kinds of conjunctions: Coordinating conjunctions and Subordinating conjunctions. Coordinating conjunctions join two clauses or sentences of equal rank. Here both clauses are capable of being principal clauses if they appear 
as such in separate sentences. A Subordinating conjunction joins a principal or main clause and a subordinate clause.

Students sometimes add too many conjunctions because they do not remember exactly how many clauses they have written. Therefore, before you submit your work, you have to edit it and make sure that you have the correct number of clauses. Read the following sentence.

Incorrect: I think that the new supermarket which will improve the economy and create more jobs.

Correct: I think that the new supermarket will improve the economy and create more jobs.

This sentence contains the unnecessary conjunction which. Because of the conjunction 'which' the dependent subject of the noun clause ('the new supermarket') has no verb. The clause 'which will improve the economy and create more jobs' is an adjective clause modifying the noun 'supermarket'. As a result of this the noun clause is incomplete. By removing which you can also remove the adjective clause and create a complete noun clause: that the new shopping mall will improve the economy and create jobs.

More examples are given below:

- Incorrect: Because the new shopping mall will improve the economy and create jobs, so I support it.

This sentence has just two clauses, but it also has two conjunctions. Since one clause in the sentence must be an independent clause, it must not have a conjunction. In other words, if a sentence has just two clauses, we need only one conjunction.

- Correct: Because the new shopping mall will improve the economy and create jobs, I support it.

- Correct: The new shopping mall will improve the economy and create jobs, • so I support it.

If a sentence has three clauses, we need just two conjunctions.

- It was Copernicus who proved that the sun was the center of the universe. (Three clauses and two conjunctions) (references 15-06-2020https://www. englishgrammar.org/mistakesconjunctions/).

Students often make the mistake of using the relative pronoun that before interrogatives like what, where, when, whether and why.

Incorrect: Do it carefully lest you may not make a mistake.

Correct : Do it carefully lest you make a mistake.

Lest means that...not, and, therefore, it will be wrong to add another not in the following clause. It should also be noted that the only auxiliary verb that can be used after lest is should.

Incorrect: He climbed up a tree such as to get a good view of the procession.

Correct: He climbed up a tree so as to get a good view of the procession.

When a negative expression comes at the beginning of a sentence, we use an inverted word 
order. That means the auxiliary verb comes before the subject.

- Incorrect: Unless you do not apply the job, you will never get it.

- Correct: - Unless you apply the job, you will never get it. Unless means if...not. Therefore it is wrong to use another not in a sentence with unless.

- Incorrect: There is no such good restaurant which you mention.

- Correct: There is no - such good restaurants you mention. Incorrect: The teacher asked me to avoid the bad habit.

- Correct: The teacher asked me to avoid the bad habit such as noisy in class discussion.

Other examples:

- Incorrect: Ana did not come to my birthday party. Because she was angry.

- Correct: Ana did not come to my birthday party because she was angry.

This is a common punctuation mistake. Because is a subordinating conjunction and must never be separated from its main clause by a full stop.

- Incorrect: No sooner I had met him than the car left.

- Correct: No sooner had I met him than the train left.

When no sooner comes at the beginning of a sentence, we use an inverted word order. That means the auxiliary verb comes before the subject.
- Incorrect: The car door was open and there was nobody in.

- Correct: The car door was open but there was nobody in.

But is the conjunction to use when the second main clause gives unexpected information.

- Incorrect: Because Ari is cleaver so he gets good results.

- Correct: Because Ari is cleaver he gets food results.

Because is conjunction, it doesn't require a second conjunction.

- Incorrect: Since Lia was bad mood and I said nothing.

- Correct: Since Lia was bad mood I said nothing.

Since is conjunction and it is enough to join the two clauses.

- Incorrect: Budi did not come to class today. Because he is late.

- Correct: Budi did not come to class today because he is late.

This clause cannot stand alone. It must be attached to independent clauses.

Kind of Conjunctions can be classified into following main kinds:

1. Co-coordinating Conjunction Those conjunctions that join two independent statements are known as coordinating conjunctions. These two statements are usually of equal rank.

a. Askar went to market and Hasan went to beach. 
b. Ipin is relax, but he is very smart. (express contrast between the two sentences it is joining is known as an adversative conjunction).

c. Singh should try hard, or he will fail (it is expressing the choice between the two sentences it is joining).

d. He must not have bad thinking, for he loosed his things. (it is showing an inference in the second sentence from the acts in the first sentence).

\section{Subordinating Conjunction Those conjunctions} that join two sentences which is dependent on the other.

a. Julian looks the view as a beautiful subject because it interesting. (it is introducing the dependent clause "it interests interesting" to the main sentence "She looks the view as a beautiful subject".

b. I and Ari found after the he had gone (It refers to time).

c. Ahmad may join the club, as he is a partner (it refers to cause or reason)

d. They work so that they are rich. (refers to purpose)

e. Nasir was so strong that he could break the wood (refers to consequence)

f. She will come if you come. (refers to condition)

g. Hasan is smart than Ramli.

Use of some of the important Conjunctions: and, as well as, not only ..... but also are used to join two or more words, phrases or clauses of the same nature of rank. a. Ahmad written a letter and sent it to his brother.

b. Rafi and Ali went to restaurant.

c. Andi as well as his friends are happy.

d. He was not only cleaver but also friendly. (With as well as, the verb agrees with the irst subject)

But, still, yet, express contrast between two statements. These are used to join such statements or clauses that oppose each other in thought.

a. Brian is cleaver, but arogan.

b. Grandfather is ninety years old, he still is strong.

c. Hasan studied hard, yet failed the examination. Nevertheless also expresses the same sense.

d. Today was very hot, nevertheless he did exercise.

Or, either, nor, neither express a choice/ alternative between two things. Neither ..... nor means not one, not the other.

a. Azril will visit grand-mom tomorrow or the next day.

b. Either he or his friends helped it.

c. And was neither failed nor advised.

As, since, because, for express cause or reason.

a. Ali did not go to join the soccer club as Rudi was ill.

b. I will help you since you are difficult to solve the problem.

c. The bird is singing because it is good day.

After, before, when, while, till/ until, since, for, as soon as, so/ as long a etc. express time. 
a. Some people work hard while others haven't enough.

b. Irsa has been here since 1960 .

c. Rasya will wait here until I visit.

d. You will not meet him unless you look around there.

e. As long as there is green, there is hope for plant.

f. Rudi is a boy as far as I know.

That, so that, in order that, lest express purpose or effect/ result.

a. I am so happy that I can easy finish the exam.

b. Take time lest you should finish the test. (Lest is always followed by should)

c. She informed you in order that we can easy arrange the time.

If, unless, whether, provided that, in case express condition.

a. Lisa will read the report if she get it.

b. Nela can take the bag provided that you give it.

c. Ali will go there whether I agree or not.

'than' expresses comparison.

a. I worked harder than I expected.

How expresses manner.

b. We will never know how Andi got it.

Hardly, Scarcely are followed by when.

c. I am so weaked that I can hardly stand.

d. He was scarcely six years old when his mother died. (references20-06-2017:

https://argetstudy.com/languages/english/conjunc tions.htm)

\section{List of Conjunction}

\begin{tabular}{|l|l|}
\hline A & B \\
As if & Because \\
As how & Before \\
As far as & Both \\
As much as & But \\
As long as & By the time \\
As soon as & F \\
As well as & For \\
As though & I \\
And as & If \\
E & If only \\
Either & In case \\
Even if & In order that \\
Eventhough & O \\
H & Once \\
How & Only \\
However & Only if \\
L & Or \\
Lest & S \\
N & Since \\
Neither & So \\
Nor & So that \\
Now & P \\
R & Provided \\
Rather than & Provided that \\
T & W \\
Than & When \\
That & Whenever \\
Though & Where \\
Till & Whereas \\
U & Wherever \\
Unless & Whether \\
Untill & While \\
Y & \\
Yet & \\
\hline
\end{tabular}

\section{CONCLUSION}

In general, a conjunction is an invariable grammatical particle and it may or may not stand between the items in a conjunction. Conjunction is used to make a sentence which having the cohesion and coherence in text. The absence of 
the right conjunction will result in having illogical meaning, and the message. Because of the important role of conjunctions in the writing process, this study aims to reveal the students' common errors on the use of conjunction in their writing, and investigate types of errors that occur most frequently in students' writing.

Therefore is not conjunction. It cannot connect two clauses. It is a transitional adverb. Transitional adverb should be separated from the rest of the sentences with comma (references dikutip 18-06-2020 ww.englishgrammar.org).

\section{REFERENCES}

Fukkink, R. G., \& de Glopper, K. (1998). Effects of instruction in deriving word meaning from context: A metaanalysis. Review of Educational Research, 68(4), 450-468.

Fogiel. M., (1994). REA's Hand Book English Grammar, Style, and Writing. Research and Education Association 61 Ethel Road West Piscataway, New Jersey 08854. Printed in the USA.

Graves, M. F. (2000). A vocabulary program to complement and bolster a middle-grade comprehension program. In B. $\mathrm{M}$. Taylor, M. F. Graves, \& P. van den Broek (Eds.), Reading for meaning: Fostering comprehension in the middle grades (pp. 116-135). New York: Teachers College Press; Newark, DE: International Reading Association.

Miller, G., \& Gildea, P. (1987). How children learn words. Scientiic American, 27, 9499.
National Reading Panel. (2000). Teaching children to read: An evidencebased assessment of the scientiic research literature on reading and its implications for reading instruction. Washington DC: National Institute of Child Health and Human Development.

Scott, J. A., \& Nagy, W. E. (1997). Understanding the deinitions of unfamiliar verbs. Reading Research Quarterly, 32, 184-200

Stahl, S. A., \& Nagy, W. E. (2000). Promoting vocabulary development. Austin: Texas Education Agency.

Sumber 12-06-2017: http://repository.umy.ac.id/ handle/ 